\title{
Branching and Competition in the European Banking Industry
}

\author{
Vittoria Cerasi \\ Universita' degli Studi di Milano-Bicocca \\ Barbara Chizzolini \\ Universita' Bocconi, Milano \\ Marc Ivaldi \\ GREMAQ-EHESS and Institut D'Economie Industrielle, Toulouse
}

January 2001

\begin{abstract}
In this paper we measure branching costs and competitiveness of European banks by fitting a monopolistic competition model to a representative sample drawn from nine EEC banking industries in the period from 1990 to 1996. In the theoretical model, banks decide strategically the size of their branching network anticipating the degree of competition faced on interest rates. From the structural equations of the model we derive an econometric test in order to measure branching costs and degree of competition in banking services. The empirical analysis captures their changing over time together with the impact of various European directives aiming at deregulating the banking industry. Furthermore the paper shows persistence of segmentation across EEC banking industries.
\end{abstract}

JEL classification: G21; L13; L59.

Keywords: Banking; Market structure and oligopoly; Deregulation.

Corresponding author: Marc Ivaldi - Institut D'Economie Industrielle - Université des Sciences Sociales - Manufacture des Tabacs - 21, Allée de Brienne - 31000 Toulouse. E-mail: ivaldi@cict.fr

Acknowledgments: A previous version of this paper was circulated under the title "Sunk costs and competitiveness of European Banks after deregulation" (FMG DP.290, London School of Economics). We would like to thank Bruno Biais, Giovanni Ferri, Jean-Charles Rochet, John Sutton and Jean Tirole for helpful comments and seminar participants at International Conference in Game Theory and Applications in Milan, EEA'97 in Toulouse, ASSET in Lisbon, Bank of England, IDEI and Ecole de Gestion in Toulouse, CIDE in Bologna. We thank Andrea Balzarini and Elena Carletti for extremely valuable research assistance. Financial support from Fondation Banque de France is gratefully acknowledged. 


\section{Introduction}

In the last two decades, European banking industries have undergone deregulation processes whose effects on their structures and competitive behavior have neither faded nor been entirely understood yet. Deregulation has led in a relatively short time to mergers among banks and more concentrated industries, characterized by a smaller number of larger banks that seem to offer a wider set of services to (selected) clients. ${ }^{1}$ Whether in the meantime competition among banks has become more or less fierce is a debatable and debated issue; moreover, given the complexity of the banking activity, competition in banking takes on many dimensions, as Gual (1999) and references therein very clearly outline, and each contribution in the existing literature tackles a different side of the question.

This paper addresses the joint issues of toughness of competition ${ }^{2}$ and branching behavior by banks ${ }^{3}$. In Gual's terms, branching in non regulated markets is a competitive strategy banks use to "improve access to the bank by clients", hence reduce their transaction costs and increase banks market shares ${ }^{4}$. The theoretical model (Cerasi, (1995) and (1996)) that we test in this paper accepts this definition, but it enlarges and strengthens it by modeling how entry and branching decisions by banks are linked to the type and strength of competition that is played in banking markets, along lines that are in the same class as Sutton's (1991) game theoretic model of market structure in manufacturing industries.

The main contribution of this paper is the econometric test we derived from Cerasi's theoretical model, that we use to measure and interpret the actual impact of deregulation on the banking industries of nine European countries in the years 1990 - 1996. Those were the starting years of the deregulation process in most of the countries under analysis, when they

\footnotetext{
${ }^{1}$ See Gual and Neven (1992), Economic Research Europe (ERE) Summary Report (1996), Cerasi (1996) and European Central Bank (ECB) (1999) for evidence that the degree of concentration in the European banking industry has increased since the process of deregulation has started.

${ }^{2}$ Sutton, (1991, page 9),defines toughness of competition as a "function linking concentration to prices or unit margins. This function will be affected by such featurs of the market as the physical nature of the product (..) and the climate of competition policy (a strict or acquiescent approach to price coordination by firms)."

${ }^{3}$ See, among others that deal with branching in the banking industry, Chiappori, Perez-Castrillo and Verdier (1995), De Palma and Uctum (1992), Molyneux, Lloyd-Williams and Thornton (1994), Neven and Roller (1999), Cabral and Majure (1993), Barros (1995) and Kim and Vale (1999)

${ }^{4}$ See also Neven (1989) and Cerasi (1996) for implications of deregulation on the size of branching networks.
} 
at last implemented at national level the Banking Directives, in particular the Second European Directive, issued in the eighties by the European Community in the belief that more competitive banking markets would eventually lead to more efficiency on the supply side as well as to reductions in the price of financial services for customers. The changes in regulation, by influencing either the conduct or the structure of banking markets, were also meant to provoke the removal of barriers across financial markets of EEC countries and induce a complete integration of markets both on the demand and on the supply side, a necessary occurrence in view of the adoption of the single European currency by the new millennium. Controls on interest rates have been lifted and cartels among the largest banks have been fought more fiercely, hence the power to complete on interest rates has increased for the overall banking system. Costs and legal constraints attached to entry by EEC banks into another EEC country have been reduced or altogether removed; capital controls have also been lifted, thus potentially affecting the decision to enter or open new branches across borders, altogether allowing the strategic interaction of banks rather than the regulatory framework to determine the structure of the banking industry.

Still, as said before, the effect of deregulation in Europe, (and in the US of A as well ${ }^{5}$ ) has been to decrease the number of banks and change their average dimension as well as branching network size in each banking industry, while the number of banks that opened exnovo branches in other European countries or underwent cross-border Merger or Acquisition operations is as yet very small. This may limit the expected benefits of deregulation on allocative efficiency, if the monopoly power of each bank has not decreased.

The econometric test in this paper gives some hints on how to unravel this puzzle, and on how to quantify the effects of deregulation on competition as well as on bank size. Disregarding ex-novo entry into a market (an empirically irrelevant occurrence in Europe in the years under analysis), the test is able to predict branching decisions in each of the nine European banking industries, by computing and comparing costs and benefits of opening branches by bank. In our specification, changes in costs are a direct function of some of the regulatory innovations listed above; benefits are also a function of deregulation through the effects that it had on toughness of competition on interest rates in the deposits markets. In

\footnotetext{
${ }^{5}$ See Volume 23, 1999 of the Journal of Banking and Finance for an overview of the debate on the effects of deregulation in the U.S.A.
} 
addition to deregulation indicators, both costs and benefits are functions of some bank and market specific variables.

It results that, after deregulation, the fierceness of competition in the EEC banking industries has risen, while the likelihood of opening new branches is on average smaller, with however quite significant differences in behavior across countries that suggest that convergence and complete integration are still quite far ahead. Furthermore the estimated trends in competition and branching sizes can only marginally be directly linked to the actual implementation of a specific EEC directive. We find that only capital flows liberalization had a significant impact, in particular it has increased competitiveness, while the Second European Directive had a minor impact on branching costs.

The theoretical model and the econometric test are presented in the next section. Section 3 describes sample data and the observable variables used in the econometric test. In section 4 the results are presented together with an evaluation of the goodness of the fit of the estimated model. Finally, section 5 concludes the paper.

\section{Bank branching behavior}

In the banking industry, as in many other industries, there are two relevant segments: the retail and the wholesale market. ${ }^{6}$ In the retail segment, banks mainly collect deposits and lend funds to households and firms. Incumbent banks compete for clients either by expanding their branching networks or by setting interest rates on financial services.

In the wholesale segment, banks may in addition supply a large variety of financial services, as for example underwriting of new issues, intermediation of different financial activities, etc. In the two segments, banks might differ also with respect to their size. In particular, large banks do tend to operate in the wholesale segment, where it is unlikely to find small banks. Here we focus on the retail segment where the vast majority of banks operate, irrespective of their size, and where it is easier to model strategic interactions among banks. Notice however that this segmentation in the banking industry has been changing over time and

\footnotetext{
${ }^{6}$ Bröker (1989) and Kaufman (1992) provide detailed pictures of structures and relevant strategic issues of the European banking industry.
} 
it is not so sharp nowadays as a result of the implementation of the Second European Directive that has redefined the functions of banks.

Banks, in the retail market, compete for clients by topping their rivals interest rates on deposits and by locating their branches closer to their clients. In other words, banks can exploit the fact that their clients have preferences over locations, in order to mitigate interest rates competition and earn some market power by enlarging their branching network. These two dimensions of competition are not independent: on the one hand, the larger the number of branches in a market, the tougher the competition on interest rates will be; on the other hand, the degree of competition on interest rates affects the incentive to expand the branching network through bank profits. The relation between competition on interest rates and branching must be modeled together. The solution proposed in this paper is a static noncooperative two-stage game where branching decisions are taken in the first stage, while interest rates are set in the second stage according to monopolistic competition rules.

Given the number of banks in the market, the decision of an incumbent to open branches depends on the effect that opening new branches has on its own clientele and on rivals' response to it. Opening new branches augments the demand for services to the bank (expansive effect), but it may also cause a relocation of clients either from branches of rivals, or from preexistent branches of the same bank (competitive effect). The benefits of opening new branches on profits of the bank depend very much on the relative strength of the expansive and the competitive effect.

However, opening new branches has a fixed cost, independently of the size of their operations, as for example the cost of hiring personnel, the cost of renting or buying facilities in that particular region, etc. A tougher price competition in the region reduces the expected profits of the new branch and therefore, the ability to recover the fixed costs. Then the bank, in the first stage of the game, will likely decide not to open new branches.

In the next paragraph, a formalized model of bank branching behavior, as briefly described above, is presented. To be able to derive bank specific functions of branching benefits and costs that can be then estimated using micro level data, an explicit functional form for the banks profits will be used. We wish to anticipate that no accounting data will be needed during estimation because the second stage equilibrium solution for interest rates ${ }^{7}$, hence for profits,

\footnotetext{
${ }^{7}$ See Cerasi 1995 for this result that derives from a model of monopolistic competition in which both stages are solved explicitely.
} 
ultimately only depends on market size, number of competitors and number of branches by bank

\subsection{The model}

Let us analyze the two-stage game where branching decisions are taken in the first stage, and then interest rates are set in the second stage. Solving backwards, we postulate that there exists a non-cooperative symmetric solution to the second stage of the game, namely the competition in interest rates, and that in equilibrium the profits of each bank can be characterized by a reduced-form which satisfies some regularity conditions ${ }^{8}$.

In order to understand the shape of this reduced-form for profits, remember that the decision to open branches results from a cost benefits trade-off. On one hand, opening new branches might attract new clients in the market (expansive effect). On the other hand, a new branch steals business to old branches, either by attracting new clients from competitors or from preexistent branches of the same bank (competitive effect). Not taking costs into account, the benefits of opening new branches result from the balance between expansive and competitive effect. This intuition is translated into setting that, given the outcome of the interest rate competition, overall bank profits are (i) increasing, although (ii) at a decreasing rate, in the number of branches of the bank; (iii) further, the benefits of opening a new branch in a market crowded by competitors is smaller. In other words, overall bank profits is decreasing in the number of branches of other competitors.

Given the second-stage game equilibrium profits, in the first stage of the game each bank sets optimally the size of its network equating the benefit of an additional branch to the cost of opening it. The marginal benefit of opening an additional branch is the profits gain of an additional branch, while the cost of an additional branch captures the opportunity cost, that is the cost of hiring personnel, the rent of spaces for the activities of the branch and all sorts of investment opportunities which are forgone by deciding to open a new branch.

Assume that in a market of size $S$, there are $n$ banks with $k_{i}$ branches each, where $i=1, \ldots, n$. Define the total number of branches operating in the market $N$. Let $\varepsilon_{i}$ be the cost of an additional branch which, for simplicity, we assume to be constant and independent upon the

\footnotetext{
${ }^{8}$ See Cerasi (1995) for the regularity conditions that must be satisfied by the profit function for equilibrium to obtain.
} 
size of the network. The marginal benefit of an additional branch, $M B\left(k_{i}\right)$, is obtained by taking the first order derivative of the equilibrium profits with respect to $k_{i}$.

The optimal size is given by the number of branches $k_{i}^{*}>1$ such that $M B\left(k_{i}^{*}\right)=\varepsilon_{i}$. This condition defines the optimal size for multi-branch banks. It could happen however that $M B\left(k_{i}\right)$ $<\varepsilon_{i}$ for any $k_{i}>1$. In this case bank $i$ will open only its headquarters and we define it as a unit bank.

Let

$$
\pi\left(k_{i}\right)=\frac{S k_{i}^{c}}{\sqrt{N}}
$$

be a special case of the reduced-form for the profits satisfying all required conditions, namely it is (i) increasing in $k_{i}$, (ii) concave in $k_{i}$ and (iii) decreasing in $N$. Furthermore this function is increasing in $\mathrm{S}$, that is the larger the market size the higher the profits for each bank in the market. Notice that for large $N$, the parameter $c$ is approximately equal to the elasticity of profits to own branching size. This parameter $c$, which is a measure of the profitability of an additional branch, can be more interestingly interpreted as the inverse of the degree of toughness of interest rates competition in the market. In other words, each additional branch delivers lower profits if competition in interest rates gets tougher, thus a smaller $c$ indicates higher degrees of competition. ${ }^{9}$

The marginal benefit of opening a new branch, given our specific reduced-form, is the derivative of the profit function in equation (1) with respect to $k_{i}$ :

$$
M B\left(k_{i}\right)=\frac{S k_{i}^{c-1}}{\sqrt{N}}\left(c-\frac{k_{i}}{2 N}\right)
$$

The first order condition (FOC) for branching is given by, either

$$
M B\left(k_{i}\right)=\varepsilon_{i}
$$

thus the optimal number of branches is greater than 1 and bank $i$ is a multi-branch bank, or

$$
M B\left(k_{i}\right)<\varepsilon_{i}
$$

therefore bank $i$ operates with only its headquarters and thus is a unit bank.

\footnotetext{
${ }^{9}$ The parameter c may as well capture other factors affecting the elasticity of profits to branching, as for instance shifts in demand and supply of banking services. Although some of them are captured by other variables, as for instance by the market size S, our interpretation can actually be restrictive. Still,
} 
Notice that the theoretical model is already set in a form which can be directly verified. In other words, the structural equation of the model, given by the FOC in the first stage equilibrium of the game, is a function of observable variables alone, related to the characteristics of the markets in which banks operate. Let us now characterize the distribution of branching costs and translate this simple static model into the econometric model to be tested.

\subsection{The econometric test}

Assume that bank $i$ sets its optimal branching network independently across markets and through time. Define bank $i\{i=1, . . n\}$ operating in market $j\{j=1, \ldots J\}$ at time $t\{t=1, \ldots T\}$ as a single observation (ijt). For all banks in the sample the branching network decision must fulfill either the FOC in equation (3a) or in (3b). Slightly modifying equation (2) and setting the appropriate subscripts, we can define a threshold:

$$
A_{i j t}=\frac{S_{j t} k_{i j t}^{c-1}}{\sqrt{N_{j t}}}\left(c_{j t}-\frac{k_{i j, t-1}}{2 N_{j t}}\right)
$$

Given the FOCs in equations ( $3 a$ ) and ( $3 b$ ), we have that, in equilibrium, either:

$$
A_{i j t} \geq M B\left(k_{i j t}\right)=\varepsilon_{i j t} \Leftrightarrow \Delta k_{i j t} \geq 0, k_{i j t}>1
$$

where $\Delta k_{i j t}=k_{i j t} k_{i j, t-1}$, or one of the following conditions must hold:

$$
\left\{\begin{array}{l}
A_{i j t}<M B\left(k_{i j t}\right)=\varepsilon_{i j t} \Leftrightarrow \Delta k_{i j t}<0, k_{i j t}>1 \\
A_{i j t}=M B\left(k_{i j t}\right)<\varepsilon_{i j t} \Leftrightarrow \Delta k_{i j t}=0, k_{i j t}=1
\end{array}\right.
$$

The above conditions can be restated as follows: for all expanding multi-branch banks the branching cost must be smaller than the threshold; for all shrinking multi-branch and unit banks the branching cost must be larger than the threshold.

Assume now that, for each period $t$ and market $j$, bank $i$ draws its branching cost from a random variable with density function $f_{\varepsilon}$ and cumulative function $F_{\varepsilon}$. This variable is identically and independently distributed across time, markets and banks, conditionally on a vector of exogenous variables $W_{i j t}$, to be defined in the next section. The set of inequalities,

in our sample, except for technological changes, shifts in profits are mainly due to changes in the interest rates competition. 
given by the equilibrium conditions in (5a) and (5b), can now be cast in probabilistic terms as either:

$$
\operatorname{Pr}\left(\Delta k_{i j t} \geq 0, k_{i j t}>1\right)=\operatorname{Pr}\left(\varepsilon_{i j t} \leq A_{i j t}\right)
$$

or

$$
\left.\begin{array}{l}
\operatorname{Pr}\left(\Delta k_{i j t}<0, k_{i j t}>1\right) \\
\operatorname{Pr}\left(\Delta k_{i j t}=0, k_{i j t}=1\right)
\end{array}\right\}=\operatorname{Pr}\left(\varepsilon_{i j t}>A_{i j t}\right)
$$

These probabilities can be restated as follows: a change in the network size of a bank depends upon the probability that the branching cost is larger (respectively, smaller or equal) than the threshold value. Notice that the probabilities associated to shrinking multi-branch and unit bank are identical. Note further that the assumption of independence of branching costs across time, markets and banks implies, in probabilistic terms, that each observation can be treated as an independent unit.

To move to the empirical test, we partition all observations in the sample into two disjoint subsets:

$$
E_{l t}=\left\{(i j t) \text { such that } \Delta k_{i j t} \geq 0 \text { and } k_{i j t}>1\right\}
$$

and

$$
E_{2 t}=\left\{(i j t) \text { such that } \Delta k_{i j t}<0 \text { and } k_{i j t}>1 \text {, or } k_{i j t}=1\right\}
$$

with $E_{1 t} \cap E_{2 t}=\varnothing, E_{1 t} \cup E_{2 t}=E_{t}$ and $E_{t}$ being the set of banks in the market at time $t$.

To sum up, for each single observation (ijt) in the sample, we can write one of the following probabilities, either:

$$
\operatorname{Pr}\left\{(i j t) \in E_{1 t} \mid W_{i j t}\right\}=F_{\varepsilon}\left(A_{i j t}\right)
$$

or

$$
\operatorname{Pr}\left\{(i j t) \in E_{2 t} \mid W_{i j t}\right\}=1-F_{\varepsilon}\left(A_{i j t}\right)
$$

The assumption of conditional independence of branching costs through time, across markets and banks, allows us to write the log-likelihood function for the whole sample as:

$$
\ln L=\sum_{t=1}^{T} \sum_{j=1}^{J}\left\{\sum_{i \in E_{1 j t}} \ln F_{\varepsilon}\left(A_{i j t}\right)+\sum_{i \in E_{2 j t}} \ln \left(1-F_{\varepsilon}\left(A_{i j t}\right)\right)\right\}
$$

Turning to the econometric specification, we need to choose a specific density function for the branching costs. Given that the support should be non-negative, one solution is to assume an exponential distribution with non-negative parameter $\lambda$. 
The objective of the econometric analysis is to estimate the parameters $c$ and $\lambda$, conditionally on the set of observable variables $W_{i j t}$. Furthermore, let us split the set of exogenous variables $W_{i j t}$ into two subsets, namely $W_{i j t}=\left\{x_{i j t}, z_{j t}\right\}$. We posit that the distribution of branching costs depends upon the vector of exogenous variables $x_{i j t}$ according to the following pdf:

$$
\lambda_{i j t}=\exp \left(x_{i j t}{ }^{\prime} \beta\right)
$$

while the inverse degree of competition in each market depends upon the vector $z_{j t}$ according to the pdf:

$$
c_{j t}=\exp \left(z_{j t}{ }^{\prime} \delta\right)
$$

To conclude, the objective of the econometric test, is to recover the mean of the distribution of branching costs together with the measure of the degree of competition given the set of observable variables $W_{i j t}=\left\{x_{i j t}, z_{j t}\right\}$.

\section{European banks in the sample}

The econometric test allows to separately estimate factors affecting the toughness of competition in each country from factors affecting branching costs. We have however to make a priori assumptions with little help from the theory or the empirical literature, on whether and how each of the limited set of available explanatory variables, affects competitiveness rather than branching costs. We spend the rest of the section describing the sample and the set of observable variables used in the implementation of the econometric test.

\subsection{The sample}

Our sample consists of annual data on banks in nine EEC countries, namely Belgium, Denmark, France, Germany, Greece, Italy, Netherlands, Portugal and Spain. The economic unit on which we focus is the single bank and not its single branch, because we believe that strategic decisions about the size of the branching network are taken at the bank level. Therefore, banks that have been operating for at least two consecutive years between 1990 and 1996 in the nine countries are retained from the Bank Base, a database supplied by the Bankers' Almanac, containing detailed information on each bank for all countries. 
Our sample is quite representative of the overall banking system in each country as it mimics fairly well its structure, at least according to the average branching size. (See Table 1) From Table 1 one can see that the average number of branches in the sample is comparable to the OECD figures for Belgium, Germany, and France, while, for the other countries, larger banks are slightly over sampled.

Table 1: Structure of the European banking industry - Comparison between population and sample

Average number of branches per bank (population)

\begin{tabular}{|l|c|c|c|c|c|c|c|}
\hline & 1990 & 1991 & 1992 & 1993 & 1994 & 1995 & 1996 \\
\hline Belgium & 160 & 144 & 136 & 133 & 130 & 128 & 128 \\
\hline Denmark & 15 & 22 & 22 & 21 & 20 & 19 & 19 \\
\hline France & 44 & 56 & 57 & 58 & 57 & 59 & 61 \\
\hline Germany & 46 & 47 & 48 & 46 & 48 & 49 & 50 \\
\hline Greece & 72 & 59 & 61 & 60 & 65 & 80 & 80 \\
\hline Italy & 43 & 47 & 55 & 56 & 70 & 77 & 81 \\
\hline Netherlands & 44 & 45 & 42 & 41 & 42 & 39 & 40 \\
\hline Portugal & 60 & 72 & 81 & 84 & 85 & 93 & 97 \\
\hline Spain & 159 & 165 & 162 & 163 & 164 & 164 & 172 \\
\hline
\end{tabular}

Source: Our computation based on OECD, Banks Profitability. Figures are rounded up.

Average number of branches per bank (sample)

\begin{tabular}{|l|r|r|r|r|r|r|r|}
\hline & 1990 & 1991 & 1992 & 1993 & 1994 & 1995 & 1996 \\
\hline Belgium & 174 & 170 & 167 & 166 & 170 & 173 & 199 \\
\hline Denmark & 46 & 48 & 45 & 58 & 58 & 48 & 49 \\
\hline France & 82 & 56 & 53 & 72 & 78 & 73 & 79 \\
\hline Germany & 44 & 49 & 48 & 48 & 50 & 51 & 45 \\
\hline Greece & 112 & 94 & 98 & 102 & 104 & 110 & 116 \\
\hline Italy & 83 & 101 & 102 & 108 & 111 & 134 & 151 \\
\hline Netherlands & 36 & 34 & 172 & 189 & 207 & 219 & 210 \\
\hline Portugal & 86 & 106 & 120 & 132 & 132 & 182 & 186 \\
\hline Spain & 544 & 384 & 357 & 318 & 398 & 427 & 432 \\
\hline
\end{tabular}

Note: Figures are rounded up

Table 2: Partition of observations (all countries and years)

\begin{tabular}{|l|c|c|c|}
\hline & $\begin{array}{c}\text { Number of } \\
\text { Observations }\end{array}$ & $\begin{array}{c}\text { Average } \\
k\end{array}$ & $\begin{array}{c}\text { Average } \\
\Delta k\end{array}$ \\
\hline Unit banks and branching banks with $\Delta k \leq 0$ & 1364 & 56 & -5 \\
\hline Of which: Unit Banks & 1057 & 1 & 0 \\
Branching bank with $\Delta k<0$ & 307 & 244 & -22 \\
\hline Branching banks with $\Delta k \geq 0$ & 2565 & 151 & +8 \\
\hline
\end{tabular}


Table 2 provides some statistics on the partition of observations in our sample according to branching behavior. It appears that, within the set of multi-branch banks, the majority (2565) opened new branches or kept their network size unchanged, while only a small number (307) closed branches. The two sets are balanced by the unit banks, which by definition did not change their branching behavior.

Table 3: Composition of bank observations by country (all years)

\begin{tabular}{|c|c|c|c|c|c|c|c|c|}
\hline & \multicolumn{2}{|c|}{ Unit } & \multicolumn{2}{|c|}{$\begin{array}{l}\text { Shrinking } \\
\text { multi-branch }\end{array}$} & \multicolumn{2}{|c|}{$\begin{array}{l}\text { Expanding } \\
\text { multi-branch }\end{array}$} & \multicolumn{2}{|c|}{ Total } \\
\hline Country & Number & $(\%)$ & Number & $(\%)$ & Number & $(\%)$ & Number & $(\%)$ \\
\hline Belgium & 95 & 45,45 & 31 & 14,83 & 83 & 39,71 & 209 & 100 \\
\hline Denmark & 20 & 9,66 & 47 & 22,71 & 140 & 67,63 & 207 & 100 \\
\hline France & 406 & 56,94 & 38 & 5,33 & 269 & 37,73 & 713 & 100 \\
\hline Germany & 382 & 34,11 & 102 & 9,11 & 636 & 56,79 & 1120 & 100 \\
\hline Greece & 3 & 2,83 & 6 & 5,66 & 97 & 91,51 & 106 & 100 \\
\hline Italy & 83 & 8,66 & 24 & 2,51 & 851 & 88,83 & 958 & 100 \\
\hline Netherlands & 32 & 32,99 & 9 & 9,28 & 56 & 57,73 & 97 & 100 \\
\hline Portugal & 14 & 10,00 & 6 & 4,29 & 120 & 85,71 & 140 & 100 \\
\hline Spain & 22 & 5,80 & 44 & 11,61 & 313 & 82,59 & 379 & 100 \\
\hline Total & 1057 & 26,90 & 307 & 7,81 & 2565 & 65,28 & 3929 & 100 \\
\hline
\end{tabular}

Although the majority of multi-branch banks falls into the "expanding" class, this proportion varies across countries (as can be seen in Table 3). Notice further that the structure of banking industries can be quite different as one can infer from the comparison of the percentage of unit banks across countries.

A large proportion of banks, namely $26.90 \%$, has only one branch, presumably the headquarters of the bank. Although unit banks are more likely to operate in the wholesale segment, where branches do not give any competitive edge on rivals, we consider them to be present also in the retail segment, whenever collecting retail customer deposits. Indeed, the choice of being a unit bank is a signal of higher branching costs compared to other banks that concentrate the bulk of their operations in the retail segment. 


\subsection{Mergers and acquisitions}

There have been several Merger and Acquisition (M\&A) deals in Europe over the sample period, some of them performed across national borders. ${ }^{10}$ While collecting data on banks and their branching networks by country, however we were not able to recover all M\&A deals that involved banks in our data set: the reason being that except for large public banks, it is difficult to gather the names of the banks involved in any deal. ${ }^{11}$ In the sample there are 95 banks involved in M\&A deals, 4 cases are cross-borders. (See Table 4 for the distribution of deals across countries). In 37 cases the bank was involved in a merger, while in 58 in an acquisition deal. Among the acquisitions, in 45 cases ( 2 cross-borders) the bank was active in the deal, while in 13 cases ( 2 cross-borders) it was passive.

Table 4: Banks involved in M\&As in the sample

\begin{tabular}{|l|c|}
\hline \multicolumn{1}{|c|}{ Country } & Number \\
\hline Belgium & 5 \\
\hline Denmark & 6 \\
\hline France & 11 \\
\hline Germany & 13 \\
\hline Greece & 0 \\
\hline Italy & 47 \\
\hline Netherlands & 3 \\
\hline Portugal & 0 \\
\hline Spain & 10 \\
\hline Total & 95 \\
\hline
\end{tabular}

All acquisitions recorded in our sample refer to cases where the acquiring bank gained majority control over the acquired bank. Furthermore, only major mergers were taken into account, that is mergers involving two or more medium to big banks. Finally we do not have any information on deals done in Greece and Portugal.

Even though our list of M\&A is not exhaustive, there still is a large enough number of deals to test the impact of M\&A on branching costs. Notice that in the model there is no difference between opening (or closing) a new branch or acquiring (or selling) a branch through a M\&A

\footnotetext{
${ }^{10}$ See Gual and Neven (1992), ERE Summary Report (1996) for detailed figures on cross-borders and inside borders M\&As in the last years. We refer to Danthine et al. (1999) instead for the economic analysis of cross-borders M\&As of European banks.

${ }^{11}$ Among the foreign Central Banks, we must acknolwedge a report by the Bundesbank concerning german banks, which allowed us to include in our dataset the names of many banks involved in M\&A deals.
} 
deal. We hence included in our data set a dummy variable that indicates if an observation is involved in a M\&A deal.

\subsection{Deregulation variables}

In the eighties, the institutional framework in which banks were operating has changed drastically, as a consequence of the deregulation process that has affected both banking competition and the structure of markets, through the relaxation of entry barriers within and across markets. A description of the legal framework in which banks operate is out of the scope of this paper. ${ }^{12}$

Our objective is to pin down how the changes in banking regulation influenced the degree of competition and the decision to open or close branches. Therefore we have constructed a set of dummy variables that indicate when particular regulatory rules, which should affect banks' conduct and branching decisions, have been implemented in each different country. (See Table 5) There is often a lag between the time in which a particular regulation is passed at the EEC level and the moment of its implementation at the national level. Each regulation dummy will then take on value 1 in and after the year of implementation in a specific country, rather than in the year the policy was approved at the European level. ${ }^{13} \mathrm{We}$ focus on three important measures.

The first one, capital flow liberalization $(C F L)$, is the set of policies whose target was to ease the flow of financial services across the European countries and, as a consequence, to stimulate banking business across countries. (See Art.67, EEC Treaty) We expect an increase in the demand for banking services all over the EEC and more mobility of banks as a consequence of higher capital mobility. This may affect the degree of competition, as banks envisage entry by new competitors in the market.

The second rule, interest rate deregulation (IRD), is the set of laws and policies, at the national level, aimed at increasing interest rate competition among banks. We expect to see an increase in the degree of competition. However IRD policies were enforced in six out nine countries by 1990, the starting year in our data set (with the exception of Belgium in 1991, Portugal in 1992 and Greece in 1993). Therefore their effect on competition must be checked

\footnotetext{
${ }^{12}$ See Gual and Neven (1992), ERE Summary Report (1996) and Danthine et al. (1999) for extremely helpful and complete guides on the changing banking regulatory environment.

${ }^{13}$ We took this information from the ERE Summary Report (1996).
} 
Table 5: Indicators of regulatory changes

Capital flow liberalization, CFL (Art. 67, EEC Treaty)

\begin{tabular}{|l|c|c|c|c|c|c|c|}
\hline & 1990 & 1991 & 1992 & 1993 & 1994 & 1995 & 1996 \\
\hline Belgium & 1 & 1 & 1 & 1 & 1 & 1 & 1 \\
\hline Denmark & 1 & 1 & 1 & 1 & 1 & 1 & 1 \\
\hline France & 1 & 1 & 1 & 1 & 1 & 1 & 1 \\
\hline Germany & 1 & 1 & 1 & 1 & 1 & 1 & 1 \\
\hline Greece & 0 & 0 & 0 & 0 & 1 & 1 & 1 \\
\hline Italy & 1 & 1 & 1 & 1 & 1 & 1 & 1 \\
\hline Netherlands & 1 & 1 & 1 & 1 & 1 & 1 & 1 \\
\hline Portugal & 0 & 0 & 0 & 1 & 1 & 1 & 1 \\
\hline Spain & 0 & 0 & 0 & 1 & 1 & 1 & 1 \\
\hline
\end{tabular}

Interest rate deregulation, IRD

\begin{tabular}{|l|c|c|c|c|c|c|c|}
\hline & 1990 & 1991 & 1992 & 1993 & 1994 & 1995 & 1996 \\
\hline Belgium & 0 & 1 & 1 & 1 & 1 & 1 & 1 \\
\hline Denmark & 1 & 1 & 1 & 1 & 1 & 1 & 1 \\
\hline France & 1 & 1 & 1 & 1 & 1 & 1 & 1 \\
\hline Germany & 1 & 1 & 1 & 1 & 1 & 1 & 1 \\
\hline Greece & 0 & 0 & 0 & 0 & 1 & 1 & 1 \\
\hline Italy & 1 & 1 & 1 & 1 & 1 & 1 & 1 \\
\hline Netherlands & 1 & 1 & 1 & 1 & 1 & 1 & 1 \\
\hline Portugal & 0 & 0 & 1 & 1 & 1 & 1 & 1 \\
\hline Spain & 0 & 0 & 0 & 1 & 1 & 1 & 1 \\
\hline
\end{tabular}

Second European directive, SED (1989, n. 646)

\begin{tabular}{|l|c|c|c|c|c|c|c|}
\hline & 1990 & 1991 & 1992 & 1993 & 1994 & 1995 & 1996 \\
\hline Belgium & 0 & 0 & 0 & 0 & 1 & 1 & 1 \\
\hline Denmark & 0 & 1 & 1 & 1 & 1 & 1 & 1 \\
\hline France & 0 & 0 & 0 & 1 & 1 & 1 & 1 \\
\hline Germany & 0 & 0 & 1 & 1 & 1 & 1 & 1 \\
\hline Greece & 0 & 0 & 1 & 1 & 1 & 1 & 1 \\
\hline Italy & 0 & 0 & 0 & 1 & 1 & 1 & 1 \\
\hline Netherlands & 0 & 0 & 1 & 1 & 1 & 1 & 1 \\
\hline Portugal & 0 & 0 & 1 & 1 & 1 & 1 & 1 \\
\hline Spain & 0 & 0 & 0 & 0 & 1 & 1 & 1 \\
\hline
\end{tabular}

by estimating for each country the divergence from the overall degree of competition induced by their implementation. ( Both CFL and IRD enter the set of variables $z_{j t}$ in equation 10).

Finally, the third dummy refers to the second European directive 1989/n.646 (SED). This directive has introduced the principle of single license for banks, which must facilitate entry by foreign banks across EEC markets. Furthermore by shifting the capital requirement for a bank that enters a new market, from each single branch to the bank level, we expect to see a 
reduction in the cost of opening new branches across countries, and we include SED into the set of explanatory variables $x_{i j t}$ in equation 9. Notice that the second European directive has also eliminated the classification of banks by function, in favor of universal banks, that is multifunctional banking both within and across borders.

\subsection{Inputs costs and market variables}

Costs, in particular the cost of labor and the interest rate on real capital, may affect the choice of opening a new branch, as they represent the fixed factors for branch operations. Labor cost is an important component of fixed costs in branching, as personnel is needed to run a branch and must be paid independently of the level of activity of that particular branch. More specifically, the unit labor cost in a particular region (country) must affect the decision as to whether open a new branch in that region. Therefore, we look at the way in which the real wage in the banking sector (Wage) affects the average cost of branching (equation 9), expecting a positive relationship.

Opening a branch also involves renting or buying facilities in a particular location, i.e. investing in fixed capital. The average cost of branching should increase if the real interest rates (Rirate), as a proxy for the opportunity cost of investing in fixed capital, increases. Unfortunately this proxy may pin down also other effects, as for example the costs of interbank funds or more generally an indicator of the level of economic activity linked to monetary policy, and therefore the results should be carefully interpreted. If, on the one hand, the real interest rate were to capture the cost of funds in the interbank market, we should expect a negative correlation with the cost of branching, as a rise in the interbank rate increases the convenience of collecting funds through branches. On the other hand, since real interest rates are directly related to monetary policy, when economic activity grows we expect interest rates to be low and competition for clients among banks to be softer, hence a positive relation between real rates and degree of competition. Only the results of estimation will tell which of the two effects, the one on competition or the one on branching costs is the most relevant.

Finally in computing the threshold variable $A_{i j t}$, (4), for each country, we use total deposits as a proxy for market size, $S$, while $N$ is the total number of branches in the country. For each bank in the sample, we have the number of branches, $k$. Table 6 provides the average values for the exogenous variables included in the econometric model. 
Table 6: Average values of main variables over the sample period

\begin{tabular}{|l|r|r|r|r|r|}
\hline & \multicolumn{1}{|l|}{} & \multicolumn{1}{l}{$l$} & \multicolumn{1}{l|}{$k$} & \multicolumn{1}{l|}{ Wage } & \multicolumn{1}{l|}{ Rirate } \\
\hline Belgium & 20.97 & 18148.9 & 177.0 & 61.4 & 4.7 \\
\hline Denmark & 7.99 & 2421.2 & 52.3 & 44.2 & 5.6 \\
\hline France & 75.45 & 25969.8 & 71.6 & 56.3 & 4.8 \\
\hline Germany & 132.88 & 42224.7 & 49.1 & 41.3 & 4.0 \\
\hline Greece & 3.91 & 1272.4 & 107.6 & 24.1 & 5.1 \\
\hline Italy & 61.38 & 18976.1 & 114.4 & 71.9 & 5.8 \\
\hline Netherlands & 29.60 & 7194.3 & 178.2 & 59.7 & 3.3 \\
\hline Portugal & 6.47 & 2973.8 & 139.6 & 25.0 & 5.3 \\
\hline Spain & 44.10 & 35825.3 & 401.0 & 49.5 & 5.4 \\
\hline
\end{tabular}

Note: $S=$ National deposits (millions US\$, constant prices); $N=$ Total number of branches; $k=$ branches per-bank; Wage $=$ real wage rate in the banking sector (thousand of US\$); Rirate = Real interest rate.

\section{Results}

The maximization of the $\log$-likelihood function (8), with $\mathrm{F}_{\varepsilon}($.$) assumed to be an exponential$ distribution, is performed by a non-linear optimization routine provided by the statistical software package GAUSS. In terms of the theory of Pseudo Maximum Likelihood (see Gouriéroux and Jouneau, (1993)), given that the density function belongs to the exponential family, parameters are consistently estimated. However, the assumption of independence across individuals, time and markets of the stochastic cost variable as well as the choice of the density are arbitrary and involve a potential problem of mis-specification. Hence we computed the White heteroskedastic-consistent covariance matrix to obtain correct standard errors of the estimates

In the rest of the section we present the results of two models, a deterministic one, in which only the time trend and country dummies were introduced in both parameters, and a non deterministic model, in which the other market and time specific variables are also used to explain the two parameters. In this section we first present some measures of the goodness of fit and then we analyze the results of the econometric test.

\subsection{Goodness of fit}

We present three measures of goodness of fit that are appropriate for binary discrete choice models such as the one we estimate in this paper. The McFadden Pseudo- $\mathrm{R}^{2}$ that we computed for both models (see Table 8), indicate that the deterministic model performs slightly better 
than the non deterministic one. It also shows that the included regressors significantly improve (by approximately $36 \%$ ) the explanatory power of both models relative to the restricted model where the probability of falling into one of the two classes of banks only depends on a constant.

To gain more insight into the predictive power of the non deterministic model, we show two additional measures of goodness of fit, $\mathrm{C}$ and $\sigma_{\mathrm{n}}$, based on the prediction/realization Table 7, that compares the observed with the estimated partition of the sample. $\mathrm{C}$, the percentage of correct predictions, indicates that the model correctly predicts the branching behavior for $80.3 \%$ of observations in the sample. Note that the incorrectly predicted observations are located outside the main diagonal of Tables 7 .

Table 7: Observed and predicted relative frequencies

\begin{tabular}{|l|r|r|r|}
\hline $\begin{array}{c}|c| \\
\text { Prediction }\end{array}$ & $\Delta k<0$ or $k=1$ & \multicolumn{1}{|c|}{ Total } \\
\hline$\Delta k \geq 0$ & $52.4(186)$ & $6.8(275)$ & 59.3 \\
\hline$\Delta k<0$ or $k=1$ & $12.9(9)$ & $27.9(2)$ & 40.7 \\
\hline Total & 65.3 & 34.7 & 100 \\
\hline \multicolumn{2}{|r|}{ Goodness-of-fit: $\mathrm{C}=80.3 \% ; \sigma_{n}=59.2 \%$} \\
\hline
\end{tabular}

Note: In each cell, the figures provide the percentage of banks over the total number of observations (3929) that fall in the corresponding case. The average branching size for these banks is in brackets.

The Table is based on the predictions of the non deterministic model.

The average branching size of banks that have opened branches but the model places into the group of banks that have closed branches (see the southwest cell of Table 7) is 9, while the average branching size of banks that have closed branches and that are placed by the model into the group of banks that have opened branches (see the north-east cell of Table 7) is 275 . Hence, on the one hand, the model tends to predict that large banks are more likely to open new branches compared to small banks, on the other hand, it overestimates the number of banks that have closed branches, namely $40.7 \%$ instead of $34.7 \%$ observed cases of this type. As a matter of fact, very large banks have been closing down branches. (See Table 2 in the previous section) Thus, although the model captures quite well the average branching behavior of banks, it might underestimate factors explaining the behavior of banks at the tails of the size distribution, that is, why large banks have closed branches, while small banks have not. 
For completeness and because $\mathrm{C}$ may be misleading ${ }^{14}$, we also computed $\sigma_{\mathrm{n}}$, which can be interpreted, similarly to a $R^{2}$, as the percentage of the variability of the phenomenon that the model explains. This measure takes on a value of almost $60 \%{ }^{15}$ for our non deterministic model.

\subsection{Results of the estimation}

Parameter estimates as well as t-ratios are gathered in Table 8 , in which we present the results of two estimations. The first column refers to a completely deterministic model, while in the second column we report the results of the best, according to a cautious selection process, combination among the variables that explain the levels of the two parameters of the model, the degree of competition and the mean of branching costs.

The coefficients in the upper part of Table 8 measure the impact of exogenous variables on $c$, the elasticity of profits to branching, or, alternatively, the inverse of the degree of toughness of competition. A negative sign implies an increase in the degree of competition. We can also interpret a negative sign as inducing a lower probability that banks open new branches, namely a shrinking in the average size of branching networks. The reason is that a smaller $c$, implies a reduction in the quantity $A_{i t}$, which is the upper bound of the area defining the probability of opening new branches according to equations (6a) and (6b).

As for the parameter $\varepsilon$, a coefficient associated with the branching cost, measures the magnitude of the effect of the explanatory variable on the average cost of branching and, as a consequence, its indirect impact on the probability of opening new branches.

\footnotetext{
${ }^{14}$ See Veall et al., 1996 for a discussion of how $\mathrm{C}$ may be misleading.

${ }^{15} \sigma_{\mathrm{n}}$ is an $\mathrm{R}^{2}$ - type measure for binary prediction/realization tables that varies between 0 and 1.(See Veall et al. (1996), p.254)
} 
Table 8: Estimation results

\begin{tabular}{|c|c|c|c|c|c|c|}
\hline \multirow{2}{*}{\begin{tabular}{|l|} 
\\
Effect on parameter $c$ \\
\end{tabular}} & \multicolumn{3}{|c|}{$\begin{array}{l}\text { Deterministic } \\
\text { model }\end{array}$} & \multicolumn{3}{|c|}{$\begin{array}{c}\text { Non-deterministic } \\
\text { model }\end{array}$} \\
\hline & coeff. & t-ratio & prob. & coeff. & t-ratio & prob. \\
\hline Constant & 0,54 & 10,18 & 0,00 & 0,53 & 9,43 & 0,00 \\
\hline Dummy Belgium & $-0,27$ & $-5,44$ & 0,00 & & & \\
\hline Dummy Denmark & $-0,42$ & $-6,54$ & 0,00 & $-0,34$ & $-5,90$ & 0,00 \\
\hline Dummy Germany & $-0,09$ & $-2,04$ & 0,02 & $-0,03$ & $-0,96$ & 0,17 \\
\hline Dummy Greece & $-0,15$ & $-1,72$ & 0,04 & & & \\
\hline Dummy Italy & $-0,12$ & $-2,32$ & 0,01 & $-0,05$ & $-1,05$ & 0,15 \\
\hline Dummy Netherlands & $-0,21$ & $-3,35$ & 0,00 & $-0,17$ & $-3,04$ & 0,00 \\
\hline Dummy Portugal & $-0,14$ & $-2,12$ & 0,02 & & & \\
\hline Dummy Spain & $-0,33$ & $-6,77$ & 0,00 & $-0,29$ & $-6,86$ & 0,00 \\
\hline Time trend & $-0,02$ & $-2,81$ & 0,00 & $-0,01$ & $-1,69$ & 0,05 \\
\hline IRD Belgium & & & & $-0,11$ & $-2,60$ & 0,00 \\
\hline IRD Greece & & & & 0,12 & 1,27 & 0,10 \\
\hline IRD Portugal & & & & $-0,09$ & $-1,83$ & 0,03 \\
\hline$C F L$ & & & & $-0,06$ & $-2,54$ & 0,01 \\
\hline Rirate & & & & $-0,01$ & $-0,98$ & 0,16 \\
\hline Effect on branching cost $\varepsilon$ & coeff. & t-ratio & prob. & coeff. & t-ratio & prob. \\
\hline Constant & 3,53 & 16,91 & 0,00 & 0,18 & 0,21 & 0,42 \\
\hline Dummy Belgium & $-1,82$ & $-8,61$ & 0,00 & $-1,13$ & $-3,76$ & 0,00 \\
\hline Dummy Denmark & $-3,15$ & $-12,34$ & 0,00 & $-2,15$ & $-6,84$ & 0,00 \\
\hline Dummy Germany & $-0,33$ & $-2,02$ & 0,02 & 0,79 & 2,90 & 0,00 \\
\hline Dummy Greece & $-3,06$ & $-7,26$ & 0,00 & 0,08 & 0,14 & 0,44 \\
\hline Dummy Italy & $-1,43$ & $-6,78$ & 0,00 & $-2,01$ & $-6,44$ & 0,00 \\
\hline Dummy Netherlands & $-1,36$ & $-5,05$ & 0,00 & $-1,34$ & $-5,26$ & 0,00 \\
\hline Dummy Portugal & $-2,57$ & $-7,68$ & 0,00 & $-0,46$ & $-0,82$ & 0,21 \\
\hline Dummy Spain & $-2,73$ & $-12,04$ & 0,00 & $-2,08$ & $-8,88$ & 0,00 \\
\hline Time trend & 0,02 & 0,53 & 0,30 & & & \\
\hline Wage & & & & 0,06 & 3,53 & 0,00 \\
\hline$M \& A$ & & & & 0,17 & 0,71 & 0,24 \\
\hline$S E D$ & & & & $-0,02$ & $-0,27$ & 0,39 \\
\hline Mean log-likelihood & & $-0,4114$ & & & $-0,4126$ & \\
\hline Pseudo-R² & & $36,3 \%$ & & & $36,1 \%$ & \\
\hline
\end{tabular}

Note: all coefficients measure the distance from the benchmark, i.e. France

In the rest of the section we concentrate on the estimated coefficients of the non deterministic model. At the beginning of the 1990 integration among European financial markets was far from being achieved and banking industries were still very different across countries, mainly for historical reasons. To test for the degree of segmentation, or lack of integration, in addition to the differences captured by the institutional changes in the years analyzed in our sample, we allow in the empirical analysis the degree of competition to be different across countries. As a matter of fact, the country dummies are highly significant for 
the parameter measuring interest rate competition. Thus, we take this as evidence that starting conditions of price competition across countries were significantly different in 1990 and must be taken into consideration. Notice further that we have set France as the benchmark country to which other countries have to be compared. It follows that competitive conditions in Italy and Germany are not significantly different from France.

The time trend for the parameter $c$ is negative, so that competition becomes fiercer with time. Note that this implies that the efficient size of branching networks decreases. This cannot be seen directly from descriptive statistics as the average number of branches per bank would indicate a positive trend, at least in some countries. (Compare to Table 1)

The effect of increasing toughness of interest rate competition does seem to be induced partly by other national deregulation policies, captured by the time trend, and partly by the capital flow liberalization (dummy $C F L$ ). On one hand, the time trend probably captures the effect of changes in regulation at the country level more than those at the European Community level. On the other hand, capital flow liberalization has certainly increased competition, by increasing integration between markets, and therefore fostering rivalry among banks.

For interest rate deregulation (IRD) we have included a dummy only for three out of nine countries since this set of policies has been implemented after 1990 only in these three countries (namely in 1991 in Belgium, in 1992 in Portugal and in 1993 in Greece). For the other countries instead the impact of IRD is absorbed by the constant. Therefore we can measure only the differential impact of IRD for the three latest countries compared to the others. The negative coefficients for Belgium and Portugal indicates that IRD has increased competition, while this has not happened yet in Greece.

Finally higher real interest rates (Rirate) induce a rise in the toughness of interest rates competition. That is competition among banks is tougher, when real interest rates are high, which is an indicator of restrictive monetary policies and thus of a low level of economic activity.

Consider now the determinants of average values of branching costs by country. The coefficient for the real wage (Wage) has a positive sign, indicating that salaries are an important determinant of branching costs.

Here, the effects of changes in the regulatory environment are weaker. The dummy indicating the effectiveness of the second European directive (SED) has a negative sign, 
although not significant, indicating that this directive has decreased the cost of opening new branches.

Finally the positive coefficient of M\&A, although not significant, indicates that for those banks branching costs are higher. This could be evidence that for banks involved in M\&As branching networks need to be restructured, due to duplication of networks, or that there are other economic reasons other than economies of scale in branching for M\&As.

\subsection{Costs and competitiveness across countries}

The econometric results have implications for the degree of competition and for the choice of branching in the different countries. Together with the values of $c$, figures on profits, marginal benefits of branching, estimated branching costs by country are shown in Table 9. While the absolute values of these estimated variables may not be entirely realistic, the ordering of the countries in terms of degree of competition and branching behavior they imply is informative and close to observed facts.

Table 9: Estimated values of competitiveness and branching costs

\begin{tabular}{|l|c|c|c|c|}
\hline & $\begin{array}{c}\text { Average } \\
\text { value of c }\end{array}$ & $\begin{array}{c}\text { Average } \\
\text { value of } \varepsilon\end{array}$ & $\begin{array}{c}\text { Marginal } \\
\text { benefit }\end{array}$ & $\begin{array}{c}\text { Average } \\
\text { profit }\end{array}$ \\
\hline Belgium & 1.33 & 12.24 & 6.89 & 3059 \\
Denmark & 1.04 & 1.66 & 1.89 & 106 \\
France & 1.47 & 28.48 & 22.68 & 10023 \\
Germany & 1.43 & 26.88 & 31.13 & 3883 \\
Greece & 1.63 & 4.98 & 28.82 & 4017 \\
Italy & 1.39 & 9.32 & 31.96 & 4855 \\
Netherlands & 1.24 & 9.65 & 9.03 & 3515 \\
Portugal & 1.41 & 3.06 & 10.93 & 1476 \\
Spain & 1.12 & 2.43 & 4.54 & 2141 \\
\hline Mean & 1.37 & 16.56 & 23.08 & 4732 \\
\hline
\end{tabular}

Note: All values are millions of US\$. The values are estimated using the non-deterministic model.

Concerning the strategic interactions among banks in the retail banking industry, note that the average estimated value for the parameter $c$ is 1.37 . So the expansive effect of branching is quite important and thus, we would overestimate the competitive effect in choosing a model of pure spatial competition to analyze the branching decision. A model of monopolistic competition turns out to be a better modeling choice at least for our sample. In addition, a value of $c$ larger than one indicates that the response of profits to branching is considerable and thus, that branching still gives banks in the retail segment an edge over competitors. This is 
also confirmed by the fact that, on average, the estimated average marginal benefit of opening an additional branch is 0.48 percent of the overall profits of a bank. ${ }^{16}$

Countries can be ordered according to the degree of competition from the estimated average values of $c$. Figure 1 shows that Greece is still behind all other countries for the low level of price competition. Germany, France, Portugal and Italy have almost similar competitive conditions, while Belgium, Netherlands, Spain and Denmark show rather high levels of competition .

The estimated average branching costs are quite different across countries. (See Figure 2) Portugal, Spain and Denmark have relatively low costs of branching, whereas they are high in Netherlands, Belgium, Germany and France, with Italy in the middle. As for incentives to open new branches in these countries, we have to look at the difference between marginal benefits of branching and marginal costs. In Figure 2 we show that there is scope for opening new branches in the southern countries, Spain, Portugal, Italy and Greece, while it is not convenient in the northern countries as Belgium, France, Netherlands, Denmark and Germany.

Finally, if we were to decide where to open new branches according to our theoretical suggested model, one should look for countries where branching costs are small and toughness of competition low. In Figure 3 we have allocated countries in the branching costs-degree of competition space. The closer a country to the origin, the higher the incentives to branch in that country. So for instance, Portugal and Greece should be a better choice than Netherlands and Belgium. Further one should be indifferent between opening new branches in Spain or Denmark compared to Germany or France: it would trade off higher branching costs for lower level of competition.

\footnotetext{
${ }^{16}$ This result can be compared to Kim and Vale (1999) results for Norway. By estimating a model with conjectural variations, they show that a $1 \%$ increase in own branches bring about a $0.5 \%$ increase in market share. However they conclude that a model of pure spatial competition fits better their dataset.
} 
Figure 1: Increasing degrees of competition across countries

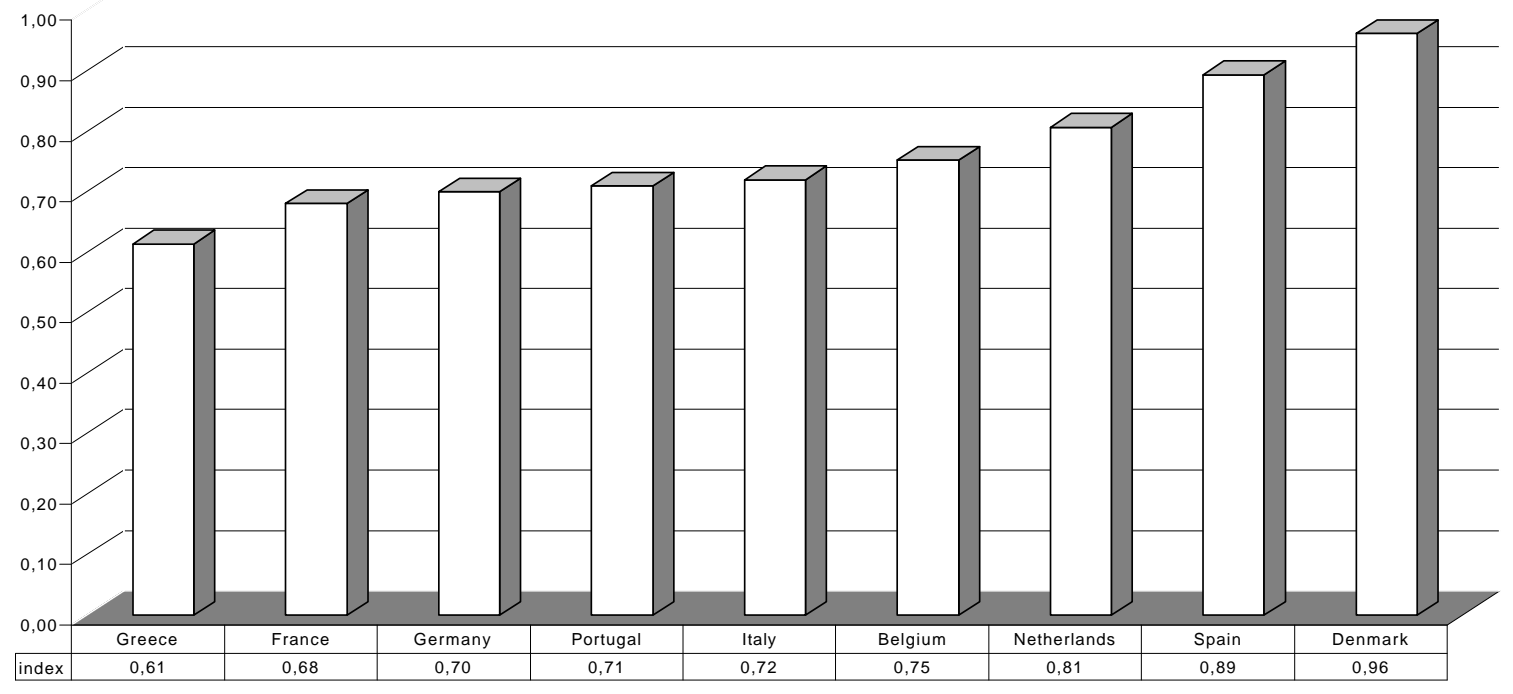

Figure 2: Marginal benefits, branching costs and their difference

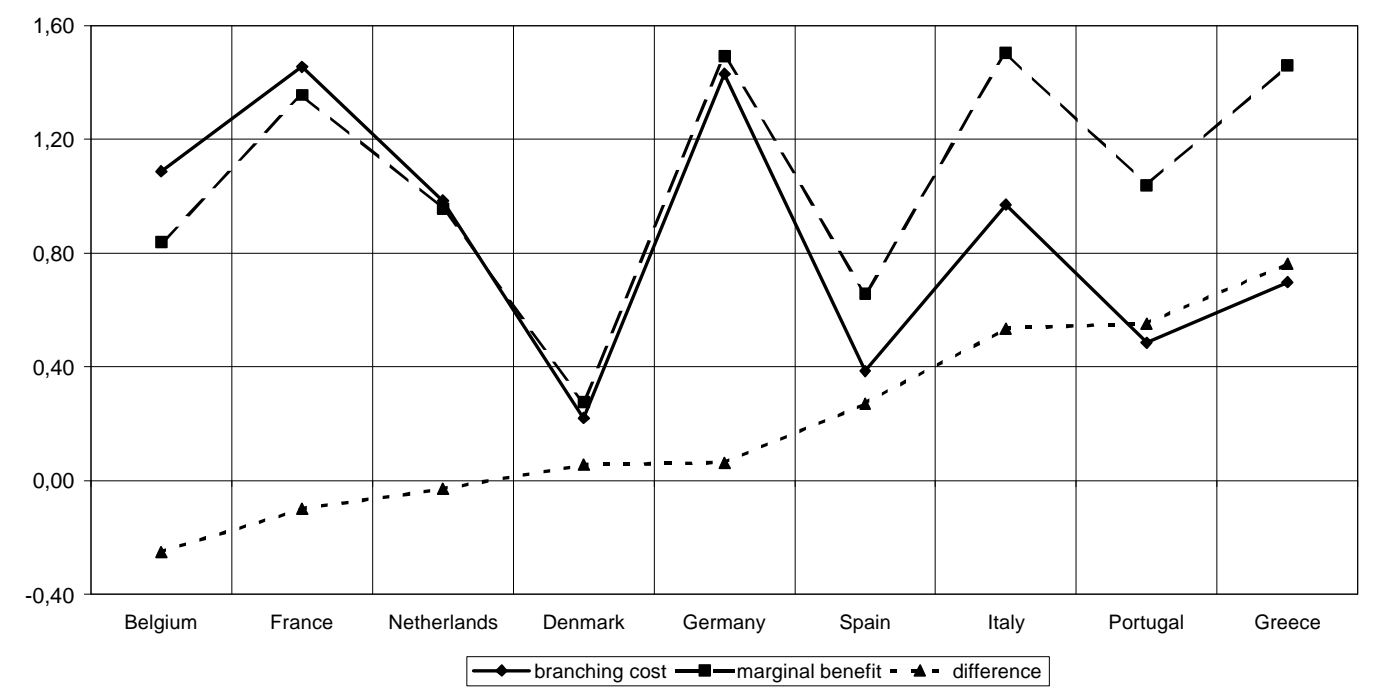

Figure 3: Location of countries in degree of competition/branching cost space

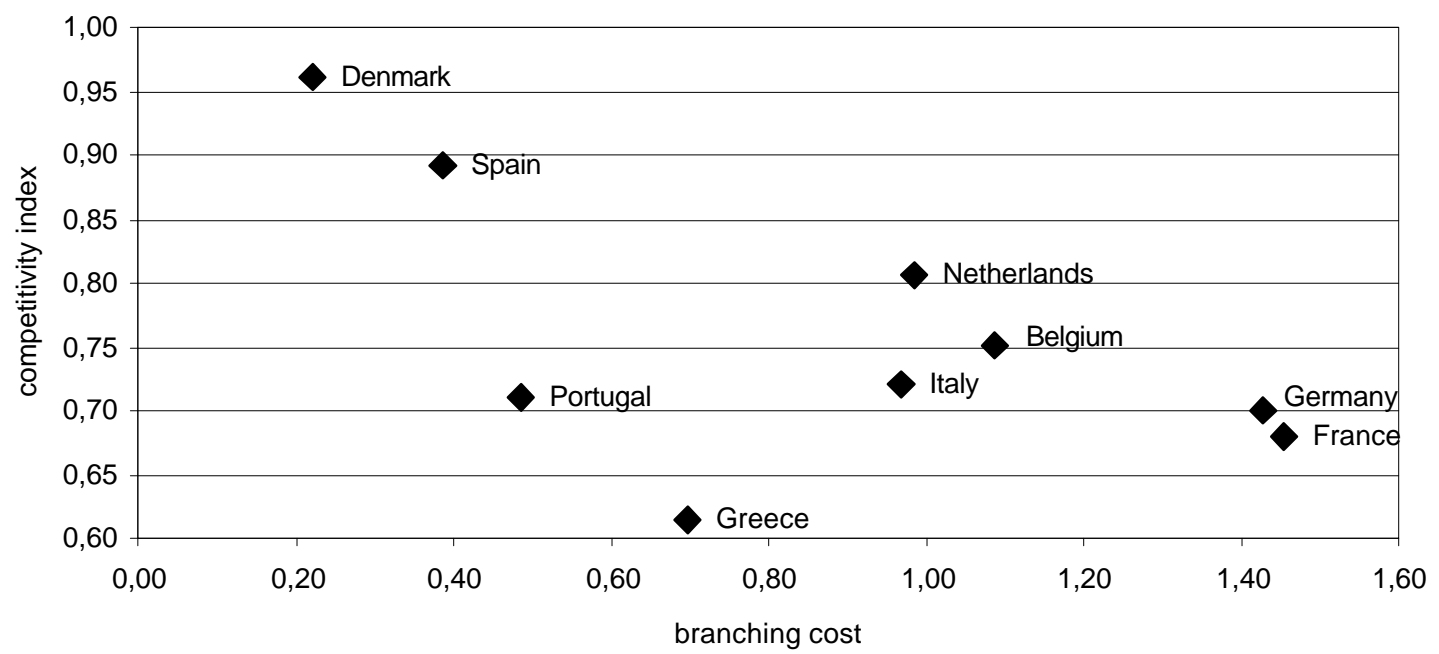

Note: The horizontal axis is in logarithmic scale. 


\section{Conclusions}

The main feature of our simple econometric analysis is to treat branching costs as a latent variable. Based on this idea, a model of monopolistic competition, fitted on microeconomic data, provides a fair approximation of the conduct of European banks. The analysis also produces a series of useful measures as for instance the degree of competition, the level of economic profits and marginal benefits of opening branches.

The results of the paper can be summarized as follows. First, deregulation has certainly increased the degree of competition within the European retail banking industry. In particular capital flow liberalization has contributed to foster interest rates competition. However the overall impact of deregulation is better captured by the time trend, that indicates increasing competition in interest rates. We interpret this as evidence that the deregulatory environment is more complex than the sum of rules passed at the European Community level. While, on one hand, these rules have pushed for an effective change of the working of the market, on the other hand, idiosyncrasies in the deregulation process at the country level play a prominent role. Second, regardless of convergence towards higher level of competitiveness there are still differences across banking industries.

Provided that data are available on entry to and exit from the industry, the level of entry costs could be estimated together with branching costs. Furthermore, with a more dynamic setting, we might be able to improve our results in this line of investigation. These extensions are part of our research agenda. 


\section{Appendix}

\section{Sources of data}

IBCA database:

Name of operating banks in each year.

The Bankers Almanac, Bank Base, several years:

Number of branches for each single bank, $k$.

Information about the history of each bank (for instance on M\&A).

OECD, Bank Profitability, last issue:

Total number of branches for each country (overall banking industry), $N$,

Labor costs in the banking sector, Wage.

IFS Yearbook, several years:

Total deposits (demand and time deposits) for each country, $S$,

Real interest rates, Rirate.

ERE Summary Report:

Dummy for implementation of interest rate deregulation, IRD,

Dummy for implementation of capital control lifting, $C F L$,

Dummy for implementation of Second EEC Directive, SED.

\section{References}

Barros, P.P., 1995, Post-entry expansion in banking: The case of Portugal, International Journal of Industrial Organization, 13, 593-611.

Bröker, G., 1989, Competition in Banking (OECD, Paris).

Cabral, L. and R. Majure, 1994, An Empirical Analysis of Bank Branching: Portugal 19891991, in: Neven, D. and Roller L., eds., The Empirical Analysis of Industrial Organization, (CEPR, London) 111-136.

Cerasi, V., 1995, A model of retail banking competition, mimeo (London School of Economics, London).

Cerasi, V., 1996, An empirical analysis of banking concentration, Quaderni del Centro Baffi, January No105 (Bocconi University, Milano).

Chiappori, P.A., D. Perez-Castrillo and T. Verdier, 1995, Spatial competition in the banking system: Localization, cross subsidies and the regulation of deposit rates, European Economic Review, 39, 889-918.

Danthine, J. P., F. Giavazzi, X. Vives and E.L. Von Thadden, 1999, The Future of European Banking, Monitoring European Integration report N.9 (CEPR, London).

De Palma, A. and M. Uctum, 1992, Financial intermediation under financial integration and deregulation, NER 19 (Banque de France, Paris).

Economic Research Europe Ltd., 1996, A study of the effectiveness and impact of Internal Market Integration on the banking and credit sector: A Summary Report. 
European Central Bank, 1999, Possible Effects of EMU on the EU Banking Systems in the Medium to Long Term (ECB, Frankfurt am Main).

Gouriéroux, C. and F. Jouneau, 1993, Pseudo Likelihood Methods, in: G.S. Maddala, C.R. Rao and H.Vinod, eds., Handbook of statistics (North-Holland, Amsterdam), 335-362.

Gual J., 1999, Deregulation, Integration and Market Structure in European Banking, CEPR, Discussion Paper No. 2288, (CEPR, London).

Gual, J. and D. Neven, 1992, Deregulation of the European Banking Industry (1980-1991), CEPR Discussion Papers, No 703 (CEPR, London).

Kaufman, G., ed., 1992, Banking Structures in Major Countries (Kluwer Academic Publishers, Boston).

Kim, M. and B. Vale, 1999, Non-price strategic behaviour: the case of bank branches, mimeo (Norges Bank, Oslo)

Molyneux, P., D.M. Lloyd-Williams and J. Thornton, 1994, Competitive conditions in European Banking, Journal of Banking and Finance, 18, 445-459.

Neven, D., 1989, Structural adjustment in European retail banking. Some views from industrial organization, CEPR Discussion Papers, No 311 (CEPR, London).

Neven, D. and L.H. Roller, 1999, Competition in the European Banking Industry: An Aggregate Structural Model of Competition, International Journal of Industrial Organization, 17 (7), 1059-1074.

Sutton J, 1991, Sunk Costs and Market Structure, (The MIT Press, Cambridge Mass., London, U.K.).

Veall M.R. and K.F. Zimmermann, 1996, Pseudo- $\mathrm{R}^{2}$ Measures for some common limited dependent variable models, Journal of Economic Surveys, 10 (3), 241-259. 